\title{
Analysis and Optimization of Cognitive Load in the Design of Online Teaching on the Internet
}

\author{
Peng $\operatorname{Han}^{1}$, Li Yang ${ }^{1}$, Liyuan $\mathrm{Xu}^{2 *}$ \\ ${ }^{1}$ Qingdao Huanghai University Art College, Qingdao, Shandong ,266555, China \\ ${ }^{2}$ Beijing Sport University, Beijing 100084,China \\ *Corresponding author. Email: $544253480 @ q q . c o m$
}

\begin{abstract}
In recent years, colleges and universities rely on the Internet to constantly improve the network classroom teaching. From the present point of view, network teaching is difficult to control students' learning initiative and attention. At the same time, the main cause of difficulty in acquiring students' knowledge in the process of network teaching is the increasing cognitive load of brain information processing. This paper analyzes the factors that produce cognitive load on students in existing network courses through the process of brain information processing and attention to dispersal effect in the process of online learning. Through the study, it is found that students' learning interest, surrounding learning environment and learning tasks are important reasons for cognitive load in the process of online teaching. Therefore, the focus of this paper is to reduce the processing of cognitive information, balance the cognitive order, and design and optimize the corresponding online classroom teaching
\end{abstract}

Keywords: Cognitive load, Network teaching design

\section{INTRODUCTION}

Online teaching has become an important part of college curriculum, but how to improve the quality of teaching online, design effective teaching methods, reduce the cognition of students under the complex knowledge structure, have become an important research content of online teaching. Cognitive load" was proposed by the Australian psychologist John Sweller in the 1970s, he believes that, he believes that cognitive load is the total amount of activity that a person exerts on an individual cognitive system when he completes an activity within a specific time[1]. According to the relevant studies, cognitive load is the level of psychological tolerance demonstrated by processing a specific amount of information[2]. As the amount of information received and processed by individuals increases, the cognitive load increases gradually[3]. Through the relevant research, it is found that the mental load of cognitive load is mainly reflected in the maximum capacity of receiving more information received by the individual over a period of time, resulting in information redundancy[4]. According to the educational psychologist's point of view, the difficulty of acquiring learners' knowledge in the course of teaching is mainly caused by the high cognitive load when the brain is processing information[5].

In the course of teaching, it is mainly shown that the students' brains have difficulty in acquiring knowledge after obtaining a lot of information and processing it. On this basis, Paas and Kester study the influence of individual knowledge structure, information characteristics and learner characteristics on cognitive load from the perspective of individual differences in teaching[6]. In

addition, in the current study of cognitive load theory foundThe effects of sound learning also include: "Free target effect", "sample learning effect", "attention to dispersion effect", "channel effect", "redundancy effect", according to the study found that the above effects of learning are mainly caused by the organization and presentation of learning materials, i.e., external cognitive load[7]. For example, sweller et al. have found that winwin using free goal problems or reducing goal clarity, the external cognitive load of learners can be reduced, while learning ability and achievement can be improved. In addition, Cooper and Sweller have demonstrated that the sample has some effect on the promotion of teaching through a series of experiments[8]. In sample learning, attention-dispersing effects have also been present, and Chandler and Sweller's research show that samples ending the content of learning are separated in time, it will separate the learner's attention and increase the cognitive load, thus interfering with the learning[9]. Use multichannel learning in the context of a large amount of information, pay attention to the consistency of information in time and space, remove excess information, and design separately according to different types of information[10]. From the above-mentioned research, it can be seen that scholars at home and abroad The problem of high cognitive load in the knowledge acquisition of the practitioners has been studied from many angles and has obtained many important results[11].

However, research on the cognitive load of Online Courses on the Internet is rarely covered. Through the author's early research, it was found that learners in the online course can not screen useful interface information in a short period of time, resulting in the brain redundancy of these information, thus forming a cognitive load, therefore, the authors design effective online teaching methods for 
the above problems through student research and experiments to reduce students' cognition under complex knowledge structure[12].

\section{RESEARCH METHODS}

\subsection{Investigation and Analysis}

This research mainly selected digital media art professi onal user experience design line class as an example, using observation method, interview method to study students, according to the author found that the online teaching process, students with screens as a medium, through visual access to information, transferred to the brain for complex information plus. Learning tasks, individual differences of students, are linesFactors that produce cognitive load in the course. First of all, the knowledge presentation of learning task is an external factor that affects students' cognitive load, and it is also a controllable variable in the teaching process. Secondly, the individual difference son of students is the internal factor that affects the cognitive load, including the difference of learner's information processing, the difference of information collected and the difference of processing rules. Therefore, learning The individual differences of the practitioners is also invariants in the teaching process. Therefore, this experiment mainly improves the teaching of online courses through the external cognitive load of the learning task.

Through the results of the preliminary investigation, the author designed three teaching courseware to improve the presentation of learning task knowledge, and carried out experimental analysis of three types of coursework. First, graphic visualization is mainly the knowledge point drawing into a visual graphics to present, through different structures under the graphics to teach. Second, text visualization is mainly in the form of text Visual presentation is mainly a way of teaching text messages in the form of mesh and flow charts. Third, the mixed visualization of graphs is mainly graphic as the theme, text complements the teaching.

\subsection{Experiment design}

This experiment uses 2 (knowledge structure: difficult, easy) x 3 (task type: graphic visualization, text visualization, text mixed visualization) multi-factor hybrid experimental design. Among them, the knowledge structure is the inter-subject factor and the task type is the factor of the subject. Dependent variables are indicators of cognitive load, including measurement of cognitive load index, task completion time, and responseaccuracy, etc.

\subsection{Subject and Experimental Tools}

From the university's digital media art students, 40 people were randomly selected to participate in the experiment, the age of the subjects between the ages of 18-20, the average age is $18.74 \pm 1.42$ ages, 20 boys, 20 girls. All subjects had normal vision (or corrected vision) and were right-hand and volunteered. The experiment was carried out on the Lenovo desktop computer, and the test materials were mainly tested courseware and test topics. Test courseware for online video provided to students for learning, test topics are mainly through learning courseware, measurement testing and correct rate, etc., and record task data.

\subsection{Experimental procedure}

The experiment is divided into two groups, each group of 20 people (10 boys, 10 girls), first of all, each group of students to learn the relevant online courses, including the task category of three courses. Second, each group takes a 30-minute break after completing the relevant course. Finally, according to the knowledge points taught in the online course, the computer test is conducted, the test is entitled fill in the blanks, the number of questions is 10The test time is 10 minutes, and information such as the student's response time and correct rate is calculated after the test. The resulting data will be summarized, the data file sissified by SPSS statistical software, and the data will be described and analyzed, related analysis, factor analysis, etc.

\section{RESULT ANALYSIS}

\subsection{Cognitive load measurement results}

Based on the experimental data, the cognitive load of the above groups is analyzed and the description statistics are shown in Table 1

Table 1 Descriptive results of cognitive load measurement in each group

\begin{tabular}{cccccc}
\hline $\begin{array}{c}\text { knowledge } \\
\text { structure }\end{array}$ & Types of tasks & $\begin{array}{c}\text { Test average } \\
\text { time(min) }\end{array}$ & $\begin{array}{c}\text { Test reaction } \\
\text { time }(\mathbf{s})\end{array}$ & $\begin{array}{c}\text { Mean test } \\
\text { accuracy }(\%)\end{array}$ & $\begin{array}{c}\text { Number } \\
(\mathbf{n})\end{array}$ \\
\hline & Graphic visualization & $7.44 \pm 1.23$ & $46.28 \pm 0.23$ & $94.66 \%$ & 10 \\
Difficult group & Text visualization & $8.32 \pm 1.17$ & $52.28 \pm 0.67$ & $90.19 \%$ & 10
\end{tabular}




$\begin{array}{cccccc} & \text { Mixed Visualization } & 7.02 \pm 0.73 & 45.37 \pm 0.23 & 97.50 \% & 10 \\ & \text { Graphic visualization } & 7.29 \pm 0.86 & 45.81 \pm 0.72 & 96.38 \% & 10 \\ \text { Easy group } & \text { Text visualization } & 8.33 \pm 0.61 & 49.42 \pm 0.45 & 92.25 \% & 10 \\ & \text { Mixed Visualization } & 7.18 \pm 0.48 & 45.22 \pm 0.33 & 98.38 \% & 10\end{array}$

From the descriptive statistical results of Table 1, it can be seen that the tests of each group vary little from the different task types, but the test results in the course teaching based on "text visualization" are worse than those of other test results when the test response is average and the test accuracy mean. At the same time, the overall test results of groups with difficult knowledge structure were

lower than those of the group with the difficult knowledge structure. On the whole, the subjects, in the process of cognitive load measurement, can take the test reaction timing and test accuracy mean as the objective indicators of cognitive load in the course of completing various tasks.

\subsection{Test completion time analysis}

Table 2 Comparison of descriptive results of test completion time and their differences(M \pm SD\&F)

\begin{tabular}{ccccc}
\hline Types of tasks & Difficult group & Easy group & F & p \\
\hline Graphic visualization & $48.43 \pm 1.78$ & $46.21 \pm 1.13$ & 0.41 & 0.332 \\
Text visualization & $54.35 \pm 1.71$ & $49.28 \pm 0.67$ & $3.23^{*}$ & 0.012 \\
Mixed Visualization & $47.02 \pm 1.37$ & $45.37 \pm 0.23$ & 0.12 & 0.586
\end{tabular}

Note: $* \mathrm{P}<0.05$ indicates significance, and the unit of task completion time is seconds

Throughg the completion time analysis of the test, it was found that the difference was not significant in the test of graphic visualization and graph mix visualization $(\mathrm{p}>$ 0.05), the difference was significant in the text visualization test, and the time of testing the difficulty group was significantly longer than that of the test low- difficult group group $(\mathrm{F}=3.23, \mathrm{p}<0.05)$, which was basically consistent with the descriptive results of cognitive load measurement.

Table3 Comparison of descriptive results of test scores and their differences under different task type

\begin{tabular}{ccccc}
\hline Types of tasks & Difficult group & Easy group & $\mathbf{t}$ & $\mathbf{p}$ \\
\hline Graphic visualization & $10.76 \pm 2.23$ & $11.44 \pm 3.27$ & $2.42^{*}$ & 0.036 \\
Text visualization & $4.83 \pm 1.23$ & $3.86 \pm 1.35$ & $-3.32^{* *}$ & 0.002 \\
Mixed Visualization & $9.62 \pm 1.73$ & $9.37 \pm 0.23$ & $2.05^{*}$ & 0.044 \\
\hline
\end{tabular}

Note: $* \mathrm{P}<0.05, * \mathrm{P}<0.01$

Under different task types, the mean and standard deviations of the test scores of the high-difficulty group and the low-difficult group group are as different as Table 3 .

The $t$ results show that the differences between the two groups are significant under three different types of tasks. Among them, in the graphic visualization, the test score of the low-difficult group group is higher than that of the high-difficult group group, in the text visualization, the test score of the high-difficult group group is higher than that of the low-difficult group group, and the test score of the two groups is basically the same in the graphic visualization.

\section{SUMMARY}

This study mainly takes learning materials as variables to examine the effects of different learning materials on learners' cognitive load and learning[13]. Three different forms of learning materials were analyzed in the experiment, and it was found that learning materials were important factors affecting learners' cognitive load and learning.In the teaching process, we should pay attention to the design and use of learning materials to reduce the cognitive load of students.. At the same time, combined with the characteristic s of Internet teaching, the use of 
dynamic teaching method is used to adjust teaching design strategy to adapt to the new mode of network teaching.

\section{FUND PROJECT}

Special topic of art education in Shandong Province "Application and Exploration of Cognitive Load Theory in the Practice of Digital Media Art Education" (Project No. YJ201911085)

2019 Qingdao Huanghai College excellent teaching team "digital media art teaching team"(Project No. HHJXTD2019002)

\section{REFERENCES}

[1] Sweller J. Cognitive load during problem solving, effects on learning $[\mathrm{J}]$. Cognitive Science, 1988,12(2):257-285.

[2] Cooper,G. Cognitive load theory as an aid for instructional design[J]. Australia Journal of Educational Technology,1990,6(1):108-113.

[3] Xin Ziqiang, Lin Chongde. The relationship between cognitive load and cognitive skills and schema acquisition and its teaching significance [J]. Journal of East China Normal University (EDUCATION SCIENCE EDITION), 2002,2(4): 55-60.

[4]Paas,F.,\&Van Merrienboer,J.J.G.Instructional contr ol of cognitive load in the training ofcomplex cognitive tasks.[J].Educational Psychology Review,1994,6(4): 351-371.

[5] Li Jing, Yu Shulan, Jin Dong. Teaching Design and Knowledge Presentation of Balanced Cognitive Load[J]. Research on Audio-Visual Education,2018,39 (03): 2328.

[6]Paas F.,\&kester.Learner and information characte rstics in the design of powerful learning environ ment[J].Applied Cognitive Psychology,2006,20(3):281285.

[7] Sun Chongyong, Li Shulian. Cognitive load theory and its application in teaching design $[\mathrm{M}]$. Tsinghua University Press, 2017.

[8] Cooper, G, \& Sweller J.The effects of schema acquision and rule automantion on mathematical problems-solving transfer[J].Journal of Educational Psychology,1997,(79): 123-134.

[9] Chandler, \& Sweller J.The split-attention effect as a factor in the design of instruction[J].British Journal of Educational Psychology,2002,62: 233-246.

[10] Zhang S J, Shi W, Liu Z.The principles of multimedia teaching design based on cognitive load theory[C]Proceedings of 2 nd international conference on education technology and computer,Shanghai,China, 2012:110-112.

[11]CGong Deying. Optimal control of cognitive load in multimedia learning [D]. Southwest University, 2009

[12] Zhao Liying, Wu Qinglin. Teaching design of complex learning based on cognitive load theory [J]. Audio visual education research, 2010 (04): 44-4

[13] Zhao Liying. Research on knowledge reversal effect in multimedia learning [D]. East China Normal University, 2014 